\title{
The Septum-Based Superomedial Pedicle Technique in Reduction Mammoplasty
}

\author{
HASHEM MOHAMED AYAD, M.D. and MOHAMED SAAD SADAKA, M.D. \\ The Department of Plastic and Reconstructive Surgery, Faculty of Medicine, Tanta University
}

\begin{abstract}
Background: In this study, we present our technique of the septum-based superomedial pedicle reduction mammoplasty using an inverted T scar pattern. It is based on the Wuringer's horizontal breast septum, through which run the main neurovascular supply to the nipple-areola complex (NAC).

Patients and Methods: The study included 35 cases with bilateral breast hypertrophy. The mean suprasternal notch to nipple $(\mathrm{SSN}-\mathrm{N})$ distance in our cases was $39.7 \pm 5.6 \mathrm{~cm}$. The mean nipple elevation in our cases was $17.9 \pm 4.6 \mathrm{~cm}$. Our mean resection weight was $764 \pm 160$ grams per side. We had 6 cases with resection weight exceeding 1500 grams per side.

Results: We had no cases of partial or total necrosis of the NAC. Immediate postoperative breast sensation was preserved in 26 cases and was impaired in 9 cases but it was regained spontaneously within 6 months.

Conclusion: The septum-based superomedial pedicle technique of reduction mammoplasty is safe technique with improved NAC vascularity and sensation, even in cases of gigantomastia, owing to the preservation of the important neurovascular structures related to the breast septum.
\end{abstract}

Key Words: Breast - Reuction - Septum.

\section{INTRODUCTION}

Breasts are a symbol of femininity. However, breast hypertrophy causes several significant problems including pain in the neck, back and shoulders, psychological problems and inframammary sulcus dermatitis [1]. Gigantomastia is severe breast hypertrophy with more than $1500 \mathrm{~g}$ of excised tissue per breast [2].

The ideal reduction mammoplasty technique produces a perfect breast size, shape, and projection with minimal scarring and preserves nipple sensation, and ability to lactate. It should also be easy, reproducible by most surgeons, expeditious and free from complications [3]. One of the most devastating complications of reduction mammoplasty is nipple-areola complex (NAC) necrosis, especially in high risk patients as diabetics, smokers, obese and patients suffering from gigantomastia.

Free nipple graft technique was described to avoid this complication when the pedicle is too long to be safe [4] and also was combined with pedicle-based breast reduction techniques. However, free nipple graft has many disadvantages as hypopigmentation and loss of sensation of NAC and loss of breast feeding potential $[\mathbf{5 , 6 ]}$.

Wuringer et al., described the horizontal breast septum and its clinical significance. The horizontal septum is the connective tissue that emerges from pectoralis fascia towards the nipple. The septum carries branches and perforators from intercostal, thoracoacromial and lateral thoracic vessels and also the lateral branch of fourth intercostal nerve [7].

In this study, we present a technique of superomedial pedicle reduction mammoplasty that is based on the horizontal breast septum to maximize the postoperative NAC sensation and vascularity.

\section{PATIENTS AND METHODS}

This study included 35 patients presented with bilateral breast hypertrophy and operated upon by the septum-based superomedial pedicle reduction mammoplasty technique using an inverted $\mathrm{T}$ scar in the period from July 2016 to December 2018.

All cases were subjected to full history taking and complete physical examination including local breast examination. Breast ultrasound was performed for patients aged less than 40 years and mammography was performed for those aged more than 40 years.

\section{Preoperative markings: (Fig. 1)}

Preoperative markings were done in the standing position starting with the midline, breast meridian, and inframammary line. The midclavicular line 
was marked below the breasts. The upper border of the breast was marked by pushing the breast upwards and marking the transition line between the breast and the chest wall contour (this helps prevent over-undermining of the breast skin flaps superiorly).

The nipple position is marked at the level of the inframammary fold and at a distance $9-11 \mathrm{~cm}$ from the midline. The breast is then pushed medially and laterally and the lateral and medial vertical limbs of the inverted $\mathrm{T}$ pattern are marked respectively to extend from the new nipple point in line with midclavicular line for a distance of $8-12 \mathrm{~cm}$ (this distance includes the areolar diameter of 2$2.5 \mathrm{~cm}$ plus the length of the vertical limb) creating an inverted $\mathrm{V}$ pattern. The horizontal limb of the inverted $\mathrm{T}$ pattern then was marked from the lower end of the vertical limb medially and laterally.

The superomedial pedicle is marked with the its width at the base at least $10 \mathrm{~cm}$, starting from the apex of areolar window. We used to create the areolar window after resection and preliminary closure is completed.

\section{Anatomical basis of our technique:}

The horizontal breast septum described by Wuringer extends from the level of $5^{\text {th }}$ rib to the nipple traversing the entire breast from medial to lateral. At its medial and lateral edge, the septum becomes more dense curving upwards to form vertically oriented ligaments, which attach the breast to the chest wall. The lateral ligament is attached to the axillary fascia at the midaxillary line (pulling on this ligament accentuates the armpit deformity) and it contains branches of the lateral thoracic artery, arising out of the $2^{\text {nd }}$ to $4^{\text {th }}$ intercostal space. The medial ligament contains perforating branches from the internal mammary artery traversing the $2^{\text {nd }}$ to $4^{\text {th }}$ intercostal spaces. Two dense layers of vessels run along the cranial and caudal surfaces of septum directed towards the nipple The cranial layer is supplied by branches of thora-coacromial artery and a branch of lateral thoracic artery. The caudal vascular layer is supplied by cutaneous perforating branches from the anastomoses of $4^{\text {th }}$ and $5^{\text {th }}$ intercostal arteries [8].

The main nerve supply to the nipple is the deep branch of lateral cutaneous branch of $4^{\text {th }}$ intercostal nerve. It arises at the lateral edge of pectoralis major muscle and runs within the retromammary space from lateral to medial for distance of 3 to $5 \mathrm{~cm}$, then changes its direction passing through breast parenchyma at the level of the caudal vascular layer and gradually superficializes to reach the nipple, always running along the horizontal septum. At the level of the $4^{\text {th }}$ intercostal space, the retromammary loose areolar tissue space, changes its direction to merge with a layer of loose connective tissue that lies cranial to the cranial vascular layer of the septum [7].

\section{Surgical technique: (Figs. 2,3)}

The procedure starts with de-epithelialization of the pedicle using scalpel. Then the breast skin flap is raised laterally with its thickness not less than $2 \mathrm{~cm}$ and is beveled to increase its thickness as the dissection proceeds laterally according to the amount of tissue to be preserved. Lateral dissection of the breast skin flaps is stopped at the anterior axillary line.

Inframammary fold incision is performed $2 \mathrm{~cm}$ above the inframammary line and dissection is performed at this level using electrocautery until the loose areolar tissue layers overlying the pectoral fascia is reached and then dissection is continued bluntly through this layer cranially until the resistance of the breast septum is felt at level of approximately $5^{\text {th }}$ rib. Attention is then turned to approaching the superior aspect of the septum by incising along the lateral vertical limb of the inverted $\mathrm{T}$ pattern and continuing the dissection deeply toward the level of approximately the $3^{\text {rd }}$ rib with electrocautery until the loose areolar tissue layer overlying the pectoral fascia is reached where blunt dissection is started along this areolar layers caudally until the septum is reached.

Resection is performed guided by the septum. As described by Wuringer, the loose areolar tissue layer of the retromammary space merges into a similar layer that overlies the cranial vascular layer of the breast septum. So blunt dissection is continued from the retromammary space to separate the breast tissue from the septum along these loose areolar tissue layers heading toward the nipple. Near the nipple, as the attachment of breast tissue to the septum becomes denser, sharp dissection is used and continues until the edge of the pedicle is reached. The amount of tissue left attached to septum is adjusted according to the postoperative volume needed. The same procedure is repeated from the inframammary incision separating the septum from breast tissues inferiorly resulting in a $\mathrm{C}$ shaped resection pattern with the majority of resection performed laterally and to a lesser extent, inferiorly and superiorly. When performing resection laterally, care is taken to stop the resection a short distance above the pectoral fascia to leave some tissue at the origin of the septum to preserve the deep branch of the lateral cutaneous branch of the $4^{\text {th }}$ intercostal nerve. After resection, the pedicle 
is remains attached to the chest wall by the central part of septum and its medial vertical ligament and part of its lateral ligament.

One suction drain was routinely placed on each side. The medial and lateral pillars are brought together with few 0 polydioxanone sutures. Then all incisions were closed in 2 layers; the dermis is closed with $4 / 0$ polygalactin sutures and the skin is closed with subcuticular 4/0 monocryl sutures. After closure of dermis of the vertical and horizontal incisions, the new areolar window is created with diameter of $4-5 \mathrm{~cm}$. and the areola is inset in the new position. After skin closure is complete, liposuction was performed, as needed, for axillary fullness.

\section{Postoperative care and follow-up:}

Drains we removed when they discharge less than $30 \mathrm{cc}$ in 24 hours and the patient is instructed
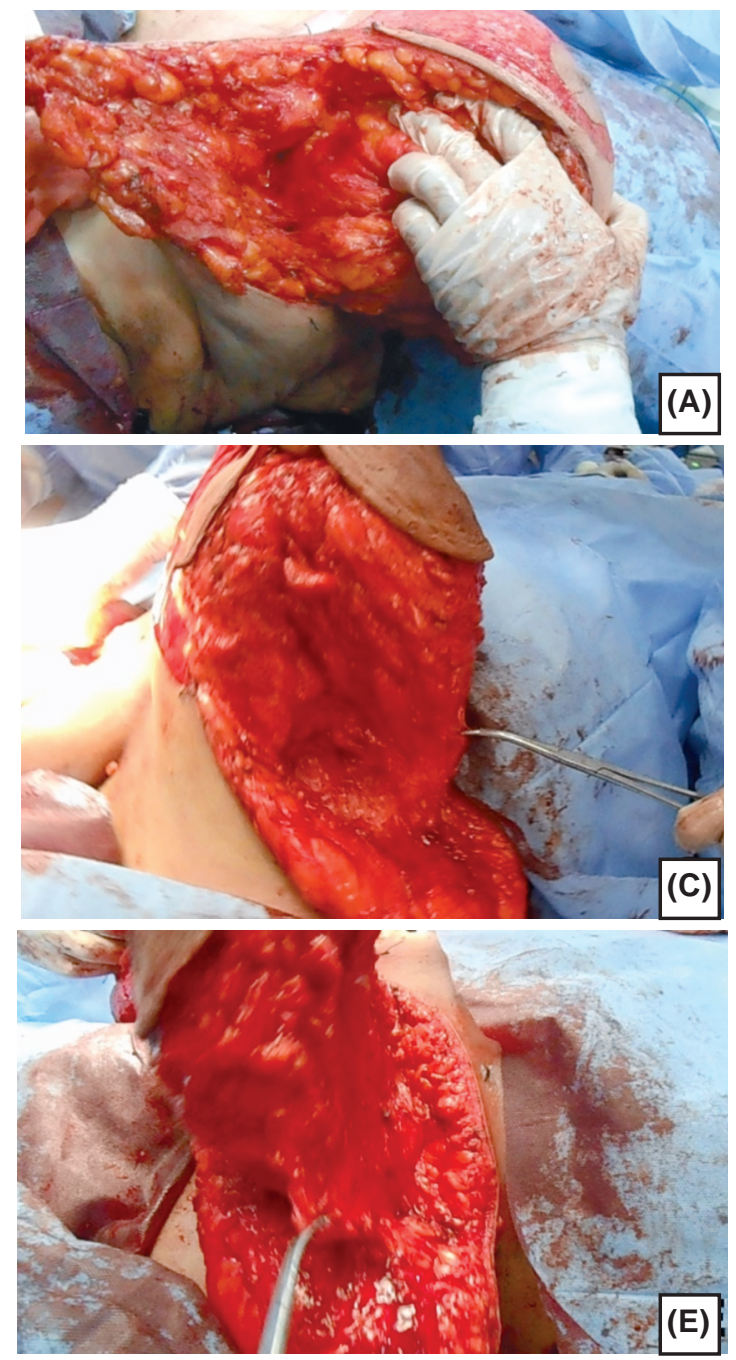

Fig. (2): (A): Incising the lateral vertical limb through skin and breast parenchyma down to the loose areolar tissue layer. (B): Blunt dissection

through retromammary space until septum reached. (C): Separating breast parenchyma from cranial surface of septum. (D): Same
procedure repeated from inframammary incision along the caudal surface of septum, (E): The septum is preserved along its whole

through retromammary space until septum reached. (C): Separating breast parenchyma from cranial surface of septum. (D): Same
procedure repeated from inframammary incision along the caudal surface of septum, (E): The septum is preserved along its whole width before resection. (F): Traction on the intact lateral ligament produces axillary dimpling. to wear a medical bra 24 hours a day for 2 months. Follow-up visits were scheduled after 2 weeks of operation, then monthly for 6 months and every 2 months thereafter.

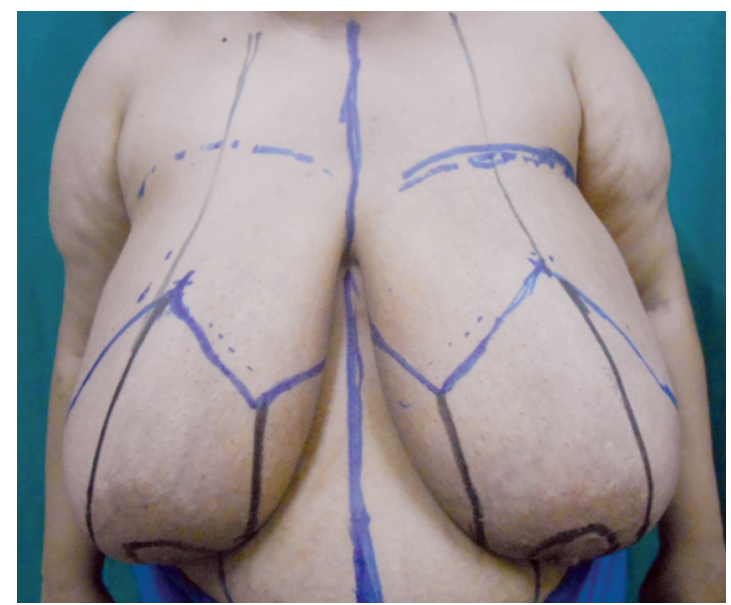

Fig. (1): Preoperative marking.
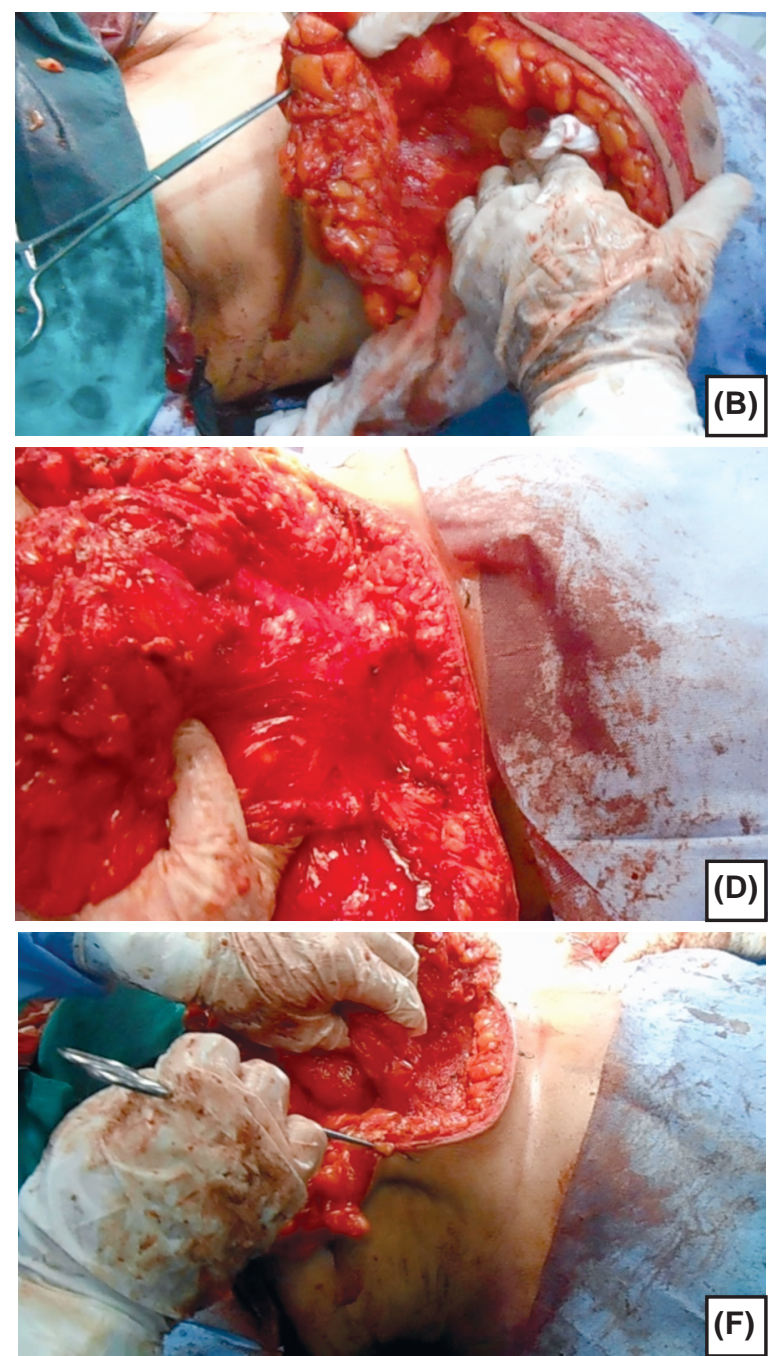
Fig. (3): Structures preserved after resection: (A): Structures running through the medial part of septum. (B): Structures running through lateral part of septum.
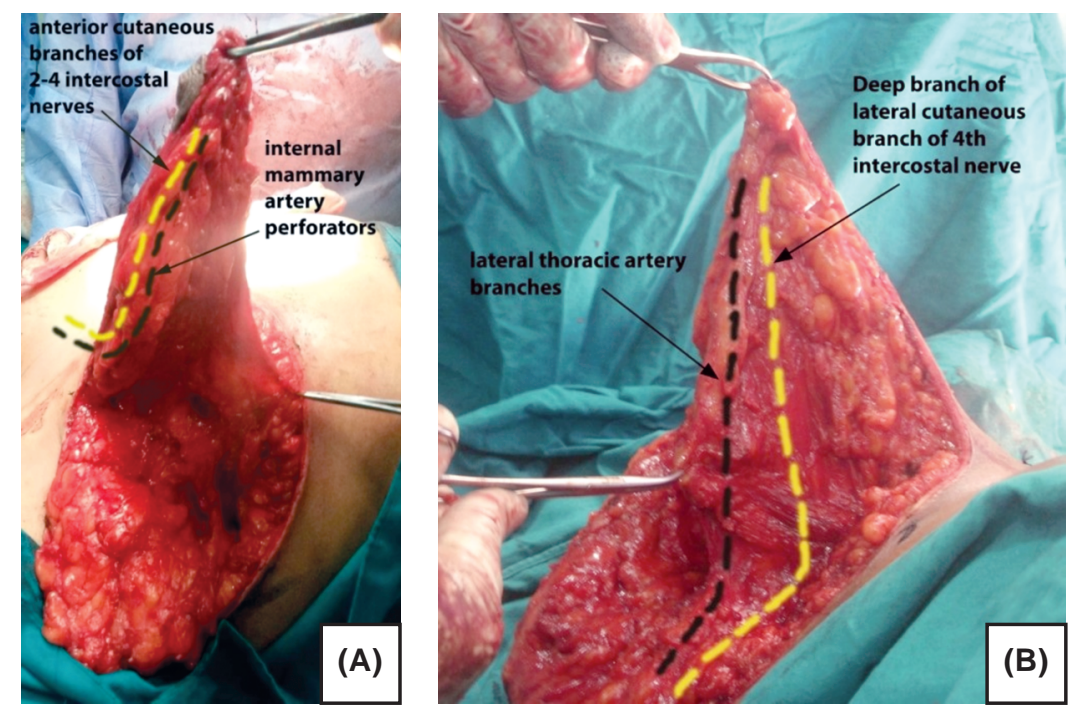

\section{RESULTS}

Figs. (4,5):

The mean age of our patients was 36 years (the youngest was 23 years and the oldest 48 years). The mean BMI of our patients was $32.2 \pm 2.15$. The mean suprasternal notch to nipple ( $\mathrm{SSN}-\mathrm{N})$ distance in our cases was $39.7 \pm 5.6 \mathrm{~cm}$. The mean nipple elevation in our cases was $17.9 \pm 4.6 \mathrm{~cm}$. Our mean resection weight was $764 \pm 160$ grams per side. We had 6 cases with resection weight exceeding 1500 grams per side. All our cases underwent bilateral breast reduction. We had no cases of partial or total necrosis of the NAC. Immediate postoperative breast sensation was preserved in 26 cases and was impaired in 9 cases but it was regained spontaneously within 6 months. We had minimal wound dehiscence in 4 (11.4\%) of cases, which occurred at the $\mathrm{T}$ junction and healed by secondary intention in all of these cases.
Fig. (4): 43 years old patient before (A) and after (B) the operation.
Fig. (5): 37 years old patient before (A) and after (B) the operation.
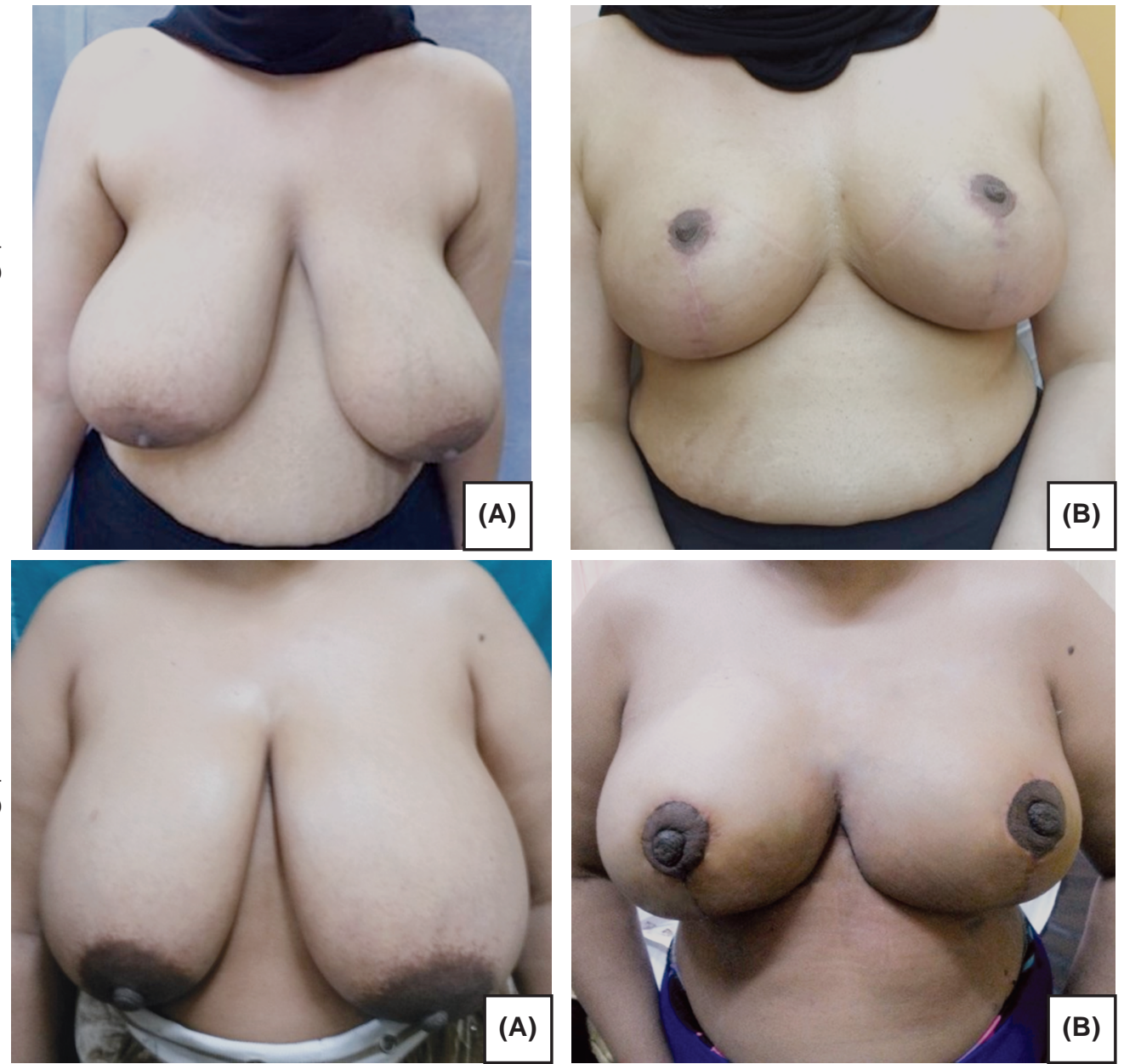


\section{DISCUSSION}

The NAC is the most important aesthetic and functional part of the breast. NAC necrosis is an infrequent but catastrophic complication that markedly impairs the aesthetic and functional results of reduction mammoplasty. The incidence of this complication was reported as $10.5 \%$ [9] and $7.3 \%$ [10].

van Deventer found that the nipple always receives one or more perforating vessels from the internal thoracic artery, therefore it is important to keep the medial vertical ligament intact as it includes these vessels. He also found that the NAC receives blood vessels from the anterior intercostal arteries in only 20 of 27 dissected breasts and receives vessels from the lateral thoracic artery in only 19 of 27 dissected breasts [11]. This could explain the occurrence of total nipple necrosis in $2.1 \%$ and partial necrosis in $7.3 \%$ of cases in the laterocentral glandular pedicle technique reported by Blondeel et al. [9].

The locations of the main sources of blood supply to NAC (internal thoracic, lateral thoracic, anterior intercostal and acromiothoracic arteries). the variation occurs as partial or complete absence of the branches from the main sources. Therefore, the blood supply to the nipple-areola complex is unpredictable and it is more safe to use a technique that includes branches from more than one main source in the NAC carrying pedicle [12]. This is what we did in our study by including the $2^{\text {nd }} 4^{\text {th }}$ internal mammary artery perforators (through the preserved medial vertical ligament of breast septum), thoracoacromial artery branches (through the cranial vascular layer of septum) and $4^{\text {th }}$ and $5^{\text {th }}$ intercostal artery branches (through the caudal vascular layer of the septum). By including 3 sources of blood supply to the breast, we had no cases of NAC necrosis in our study.

NAC necrosis occurs either due to arterial ischemia or venous congestion. Corduff et al., found that venous drainage of the breast runs from deep to superficial and centrally toward the subareolar venous plexus which, in turn, drains to the large superficial veins which continue superomedially, superolaterally, and inferiorly and join their arterial counterparts as they pierce the deep fascia medially at the $2^{\text {nd }}$ or $3^{\text {rd }}$ intercostal spaces, laterally at the lateral thoracic vessels, and in the midmammary line to the lateral-most anterior intercostal perforator in the $4^{\text {th }}$ or $5^{\text {th }}$ intercostal space. They found that venous drainage is constantly distributed, in all cases, superomedially to the $2^{\text {nd }}$ and $3^{\text {rd }}$ intercostal spaces [13]. Accordingly, the superomedial pedicle designed in our study includes one of the major and constant routes of venous drainage to the breast which is directed superomedially to the internal mammary veins. Also, the septum-based technique preserves both superficial and deep veins of the breast.

Many authors reported combining breast septum preservation with the different NAC carrying pedicles (supermedial [14], inferomedial [15], posteroinfermedial [16], inferior [17], and central [18]) and they did not have any cases of postoperative NAC necrosis. Other studies reported varying incidence of NAC necrosis when combining the preservation of breast septum with different pedicles where the incidence was reported to be $2.7 \%$ of partial necrosis with superomedial pedicle [19], 5.8\% with inferocentral pedicle [20], $0.8 \%$ partial necrosis with inferior pedicle [21] and $1 \%$ with medial and lateral pedicle [22].

The main nerve supply to the NAC is the deep branch of the lateral cutaneous branch of the $4^{\text {th }}$ intercostal nerve. In our technique this nerve is preserved as we stop the lateral resection few centimeters above the level of pectoral fascia leaving some tissue overlying it and also, we preserve the central part of the septum containing the nerve. The NAC also receives nerve supply from the $2^{\text {nd }} 4^{\text {th }}$ anterior intercostal nerves [23]. These nerves are also preserved in our technique due to the preservation of the medial breast tissue (minimal resection is done medially above and below the pedicle) and medial vertical ligament. This explains the preservation of sensation in the majority of our cases and the early return of sensation in the cases in which it was impaired immediately postoperative. Other studies on septumbased reduction mammoplasty reported preserved NAC sensation in all cases $[\mathbf{1 3 , 1 4 , 1 6 , 2 0 ]}$ or decreased in small percent of cases; (3.1\%) [17], (2.8\%) [15].

\section{Conclusion:}

The septum-based superomedial pedicle technique of reduction mammoplasty is safe technique with improved NAC vascularity and sensation, even in cases of gigantomastia, owing to the preservation of the important neurovascular structures related to the breast septum.

\section{REFERENCES}

1- Savaci N.: Reduction Mammoplasty by the Central Pedicle, Avoiding a Vertical Scar. Aesth. Plast. Surg., 20: 171, 1996.

2- Dancey A., Khan M., Dawson J. and Pearl F.: Gigantomastia, a classification and review of the literature. J. Plast. Reconstr. Aesthet. Surg., 61: 493, 2008. 
3- Movassaghi K., Liao E.C., Ting V., Matros E., Morris D.J., Orgill D.P. and Pribaz J.J.: Eliminating the Vertical Scar in Breast Reduction- Boston Modification of the Robertson Technique. Aesthet. Surg. J., 26: 687, 2006.

4- Thorek M.: Possibilities in the reconstruction of the human form 1922. Aesthetic Plast. Surg., 13: 55, 1989.

5- Karsidag S., Akcal A., Karsidag T., Yesiloglu N., Yesilada A.K. and Ugurlu K.: Reduction mammaplasty using the free nipple-graft vertical technique for severe breast hypertrophy: improved outcomes with the superior dermaglandular flap. Aesthetic Plast. Surg., 35: 254, 2011.

6- Firat C., Gurlek A., Erbatur S. and Aytekin A.H.: An autoprosthesis technique for better breast projection in free nipple graft reduction mammaplasty. Aesthetic Plast. Surg., 36: 1340, 2012.

7- Wuringer E., Mader N., Posch E. and Holle J.: Nerve and vessel supplying ligamentous suspension of the mammary gland. Plast. Reconstr. Surg., 101: 1486, 1998.

8- Wuriner E.: Refinements of the central pedicle breast reduction by application of the ligamentous suspension. Plast. Reconstr. Surg., 103 (5): 1400, 1999.

9- Lugo L.M., Prada M., Kohanzadeh S., Mesa J.M., Long J.N. and de la Torre J.: Surgical outcomes of gigantomastia breast reduction superomedial pedicle technique: A 12year retrospective study. Ann. Plast. Surg., 70: 533, 2013.

10- Blondeel P.N., Hamdi M., Van de Sijpe K.A., Van Landuyt K., Thiessen F.E. and Monstrey S.: The latero-central glandular pedicle technique for breast reduction. Br. J. Plast. Surg., 56: 348, 2003.

11- van Deventer P.V.: The blood supply to the nipple-areolar complex of the human mammary gland. Aesthetic Plast. Surg., 28: 393, 2004.

12- van Deventer P.V. and Graewe F.R.: The blood supply of the breast revisited. Plast. Reconstr. Surg., 137: 1388, 2016.

13- Corduff N., Rozen W.M. and Taylor G.I.: The superficial venous drainage of the breast: A clinical study and implications for breast reduction surgery. J. Plast. Reconstr. Aesthet. Surg., 63: 809, 2010.

14- BucariaV., Elia R. and Maruccia M.: Why Choose the
Septum-Supero-Medial (SSM)-Based Mammaplasty in Patients with Severe Breast Ptosis: An Anatomical Point of View. Aesthetic Plast. Surg., 42 (6): 1439, 2018.

15- Karacaoglu1 E. and Zienowicz R.J.: Septum-InferiorMedial (SIM)-Based Pedicle: A Safe Pedicle with WellPreserved Nipple Sensation for Reduction in Gigantomastia. Aesthetic Plast. Surg., 41: 1, 2017.

16- van Deventer P.V. and Graewe F.R.: Enhancing Pedicle Safety in Mastopexy and Breast Reduction Procedures: The Posteroinferomedial Pedicle, Retaining the Medial Vertical Ligament of Wuringer. Plast. Reconstr. Surg., 126: 786, 2010

17- Al-Shahat O.A., Al-Refae A. and Taha A.: Würinger's Septum Based Inferior Pedicle Reduction Mammaplasty. Egypt. J. Plast. Reconstr. Surg., 35: 153, 2011.

18- Bayramiçli M.: The Central Pillar Technique: A New Septum-Based Pedicle Design for Reduction Mammaplasty. Aesthet. Surg. J., 32 (5): 578, 2012.

19- Uslu A., Korkmaz1 M.A. and Surucu A., Karaveli A., Sahin C., and Ataman M.G.: Breast Reduction Using the Superomedial Pedicle- and Septal Perforator-Based Technique: Our Clinical Experience. Aesthetic Plast. Surg., 43 (1): 27, 2019.

20- Portincasa A., Ciancio F. and Cagiano L.: SeptumEnhanced Mammaplasty in Inferocentral Pedicled Breast Reduction for Macromastia and Gigantomastia Patients. Aesthetic Plast. Surg., 41 (5): 1037, 2017.

21- Kelahmetoglul O., Firinciogullari R. and Yagmur C.: Combination of Wuringer's Horizontal Septum and Inferior Pedicle Techniques to Increase Nipple-Areolar Complex Viability During Breast Reduction Surgery. Aesthetic Plast. Surg., 41 (6): 1311, 2017.

22- Hamdi M., Landuyt K.V. and Tonnard P.: Septum-Based Mammaplasty: A Surgical Technique Based on Wuringer's Septum for Breast Reduction. Plast. Reconstr. Surg., 123: $443,2009$.

23- Le Roux C.M., Kiil B.J., Pan W., Rozen W.M. and Ashton M.W.: Preserving the neurovascular supply in the HallFindlay superomedial pedicle breast reduction: An anatomical study. J. Plast. Reconstr. Aesthet. Surg., 63: 655, 2010. 